\title{
EXTINCTION AND NATICID PREDATION OF THE BIVALVE CHIONE VON MÜHLFELD IN THE LATE NEOGENE OF FLORIDA
}

\author{
Peter D. Roopnarine and Amy Beussink
}

\begin{abstract}
A morphometric discontinuity between species of the bivalve Chione during a PlioPleistocene extinction in Florida suggests that the Pliocene species $\mathbf{C}$. erosa was replaced by the immigrant $\mathbf{C}$. cancellata. Here we show that immigration of $\mathbf{C}$.

cancellata into the Florida ecosystem changed the dynamics of naticid predation on Chione. Chione cancellata, upon its first appearance in Florida, exhibited no greater degree of escalation than its predecessor C. erosa. The relative size of prey selected by naticid predators, however, declined significantly. Selected prey size subsequently increased during the Pleistocene and into the Recent, but C. cancellata has responded by significantly increasing relative shell thickness. These patterns of interaction provide direct evidence for the disruption of predator-prey systems by mass extinctions, and the microevolutionary escalation of anti-predatory traits.

Peter D. Roopnarine, Department of Invertebrate Zoology and Geology, California Academy of Sciences, Golden Gate Park, San Francisco, California 94118-4599, USA.

Amy Beussink, School of Renewable Natural Resources, University of Arizona, Tucson, Arizona 85721, USA.
\end{abstract}

KEY WORDS: Predation, drilling, naticid, Chione, extinction

Copyright: Paleontological Society, 15 March 1999

Submission: 10 October 1998, Acceptance: 23 January 1999

\section{INTRODUCTION}

The theory of evolutionary escalation predicts that if biological enemies are indeed among the most important agents of natural selection, then the interactions between predators and prey have become more escalated over geological time (Vermeij 1987). This prediction is borne out by numerous lines of evidence preserved in the Phanerozoic fossil record (Vermeij 1987). The process of escalation since the Cambrian has not been monotonic, however, because of the repeated evolution of particular modes of predation (for example, exoskeletal drilling has apparently evolved multiple times [Sheehan and Lesperance 1978; Fursich and Jablonski 1984], and perturbations resulting from mass extinctions). 
If the mechanism underlying a mass extinction generates ecological hardship within a community, then the disruption of energy supplied to that community will increase the probability of extinction for species with costly, highly developed enemy-related adaptations (Vermeij 1987). Extensive work on the dynamics of naticid gastropod drilling predation on other molluscs

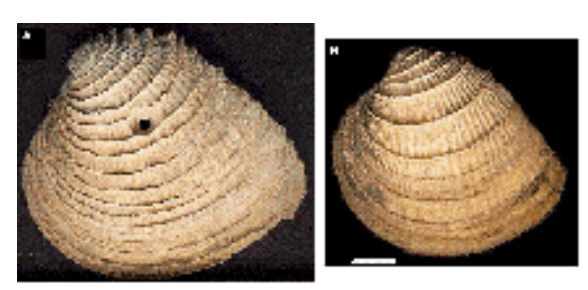

Figure 1. since the Cretaceous supports the idea that mass extinctions have interrupted the process of long-term escalation (Kelley and Hansen 1996). These studies have been conducted primarily from the standpoint of the ecological community, but similar processes may operate at the level of individual monophyletic clades that survive mass extinctions; selection will favour a reduction in the expression or frequency of enemy-related traits during an episode of mass extinction. We present here data regarding the effects of the Late Pliocene mass extinction in the southeast United States (Stanley 1986) on the relationship between a Neogene bivalve from Florida, Chione von Mühlfeld, 1811 (Fig. 1), and its naticid gastropod predators. We demonstrate that the precise interaction of extinction and escalation cannot be determined without detailed knowledge of the morphological identity of the prey species. We also present evidence supporting the microevolutionary increase of shell thickness possibly in response to drilling predation (Kelley 1991).

\section{Naticid Drilling}

Gastropods of the family Naticidae employ a stereotyped method of predation on other molluscs, including Chione. Acidic dissolution of outer shell layers, followed by radular scraping and penetration, results in a characteristic beveled or countersunk hole (Figure 2). Traces of successful and unsuccessful drilling have proven to be of enormous value to the study of predation and escalation in the geological past (Vermeij 1987; Kelley 1989; Anderson et al. 1991; Hansen and Kelley 1995). Earlier work established that naticid predators are selective with respect to drill

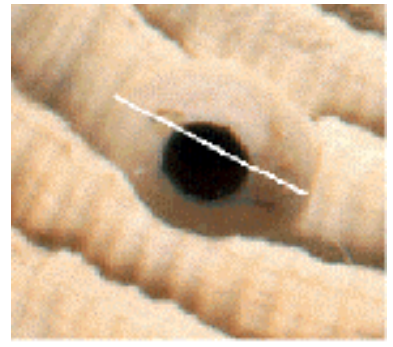

Figure 2. hole location and prey size, and that prey choice is related to such parameters of prey value and escalation as tissue mass and shell thickness (Kitchell et al. 1981). An extension of the theory of escalation (the "Kelley-Hansen hypothesis") predicts that perturbation due to a mass extinction should result in a reduction of the degree of stereotypy of a naticid predator-prey system within a community immediately following an extinction, with subsequent recovery (Kelley and Hansen 1996). This, perhaps, results from the extinction of prey species that were partners in the predator-prey system. An unanswered question, however, is the effect(s) of mass extinctions at the level of a single clade. If mass extinctions do indeed disrupt the process of escalation, then two predictions can be made concerning the Chione-naticid system: (1) selection should have favoured the survival of energetically cheaper, less escalated variation in the genus if, as commonly believed, a reduction of productivity played a role in the 
extinctions (Allmon et al. 1993; Jones and Allmon 1995; Allmon et al. 1996; Roopnarine 1996), and (2) naticid predatory behaviour should have become less stereotyped and less predictable immediately following the extinctions, in the Late Pliocene to Early Pleistocene.

\section{Neogene Extinctions in Tropical America}

The late Neogene of the tropical western Atlantic was a time of ecological upheaval as evidenced by widespread molluscan extinctions, speciation and immigration (Woodring 1966; Stanley 1986; Vermeii and Petuch 1986; Allmon et al. 1993; Vermeij and Rosenberg 1994; Roopnarine 1996; Roopnarine 1997). The proximal cause(s) of the extinctions remains unknown, although there is increasing evidence to support a precipitous decline of planktonic primary productivity associated with disruptions of regional circulation. This decline has been linked to uplift of the Isthmus of Panama (approximately 3.5 mya), subsequent termination of flow between the Atlantic and Pacific oceans, with resultant changes in oceanographic circulation and regional upwelling. The search for an extinction mechanism has focused mainly on the documentation of the intensity of the extinction (Allmon et al. 1993; Jackson et al. 1993), and the analysis of geochemical proxies of ecological factors (Teranes et al. 1996). Here, we analyze the changes exhibited by apparent survivors of the extinction episode, examining both the relationship of Chione to its naticid predators, and morphological change within the genus.

Morphological analysis of prey is an important component of the examination of predator-prey dynamics in the fossil record. Morphological differences between pre- and post-extinction populations arise from either selection-driven changes of phenotype, or the immigration of morphologically similar individuals from other geographic regions as refugees or opportunists. The analyses should be of a morphometric nature because many defensive traits (e.g., shell thickness or external sculpture) often vary continuously. In fact, there is a significant morphometric discontinuity between the Pliocene and post-Pliocene species of Chione in the southeastern United States, Chione erosa Dall 1903 and C. cancellata Linnaeus 1767 respectively, despite their overall similarity (Roopnarine 1995). Morphometric analysis of distance measures indicates that $\mathbf{C}$. erosa has a relatively larger lunule, longer shell and more dorsal disposition of the hinge when compared to C. cancellata (Roopnarine 1995). Dall (1903) originally separated the species on the basis of lunule length. There is no significant difference in size between the two species (Roopnarine 1996).

Chione erosa became extinct during the Late Pliocene, and was replaced by $\mathbf{C}$. cancellata. The morphometric distinction between contemporaneous Late Pliocene Chione specimens from North Carolina (the Waccamaw Fm.) and Florida, suggests that the North Carolina specimens are assignable to a different species, or were representative of significant intraspecific geographic variation (Roopnarine 1995). The former hypothesis is supported by the morphometric similarity between Waccamaw specimens and later Pleistocene and Recent specimens of C. cancellata from Florida, as well as South Carolina, suggesting that $\mathbf{C}$. cancellata was present in Late Pliocene 
waters north of Florida.

This raises the possibility that some extinction survivors are phylogenetically distinct "pseudosurvivors", distinguishable only by robust methods of morphometric analysis. We therefore examined the effects of the Plio-Pleistocene extinction on Chione-naticid interaction by quantifying various aspects of naticid predatory behaviour, bivalve antipredatory morphology and the morphological distinction between C. erosa and C. cancellata.

\section{METHODS}

\section{Morphometrics}

Samples of C. erosa were obtained from the following deposits and localities (Fig. 3) (sample sizes in parentheses after sample name, sample number prefixes explained at the end of this paragraph): (A) Jackson Bluff Fm. - UF7103 and UF3037 (25), Leon Co. (B) Pinecrest Beds - UF78788 (27), below Unit 8, Sarasota Co.; R016 (13), below Unit 7, Sarasota Co.; R017 (28), Unit 7, APAC pit, Sarasota Co.; R012 (12), Unit 6, APAC pit, Sarasota Co. (C) Caloosahatchee Fm. - R001 (30), La Belle. Samples of C. cancellata are as follows: (A) Bermont Fm. - R018 (27), Pit 1, Leisey, Sarasota Co.; R019 (36), Pit 3, Leisey, Sarasota Co. (B) Ft. Thompson Fm. - R010 (35), Englewood, Charlotte Co.; UF78815 (40), Englewood, Charlotte Co. (C) Anastasia Fm. - 777T (17), Palm Beach Co. (D) Recent -

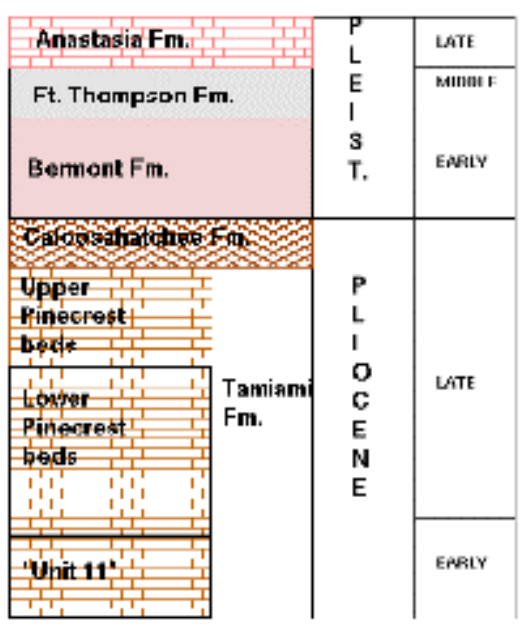

Figure 3. Lake Worth (30), Palm Beach Co. Sample prefixes are: R - author's collection; UF - Florida Museum of Natural History; T - Tulane Paleontological Collections (samples now at UF). 


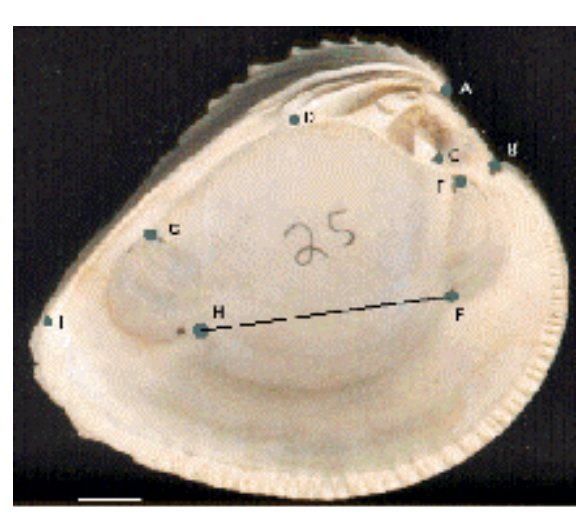

Figure 4.

All samples were analyzed morphometrically using a geometric approach to separate samples of C. erosa and $\mathbf{C}$. cancellata, and also to interpret the morphological differences between the two species. Left valves were imaged using a flatbed scanner (Hewlett Packard ScanJet Ilcx), and landmark locations digitized with image analysis software (Mocha version 1.2, Jandel Scientific). All landmarks selected for analysis originate from either the hinge region or the adductor muscle scars (Fig. 4), with the exception of the ventral ends of the lunule and escutcheon. These landmarks represent a mixture of Type I and Type II geometric landmarks (Slice et al. 1996) and are identical to those used by Roopnarine (1995) to generate inter-landmark distance measures.

The digitized landmarks were converted to shape coordinates (Bookstein 1991) by a process of translation, rotation and reference to a common baseline. This procedure effectively separates shape and scale information, with specimen size being recorded separately as Centroid Size (Bookstein 1991). Each specimen of all samples was then compared to a Procrustean consensus reference form (Rohlf 1996), and the comparison decomposed into uniform (affine) and non-uniform (non-affine) components using TPSRELW (Rohlf 1997). Uniform and non-uniform transformations are independent descriptors of shape, and represent global affine shape differences and non-affine localizable shape differences respectively. Uniform shape transformations summarize deviation from the consensus reference form as an affine transformation (Bookstein 1991; Slice 1996), decomposing the transformation into stretching and shearing components. Non-uniform transformations ("partial warps") on the other hand describe non-affine localizable shape differences. Distribution of the consensus' landmarks in Kendall shape space (Kendall 1986) is summarized by a series of tangential "principal warps". The distribution of a specimen on the Euclidean projection of the principal warps is in turn summarized by a series of partial warps, which describe the non-uniform transformation of consensus form to specimen. Non-uniform transformations can be visualized by the now well known thin plate spline diagrams.

Specimen scores on the uniform and non-uniform components were used as shape variables in conventional multivariate analyses of variance (MANOVA) and canonical variates analyses (CVA). There were no significant shape differences among the samples obtained from a single formation, so those samples were combined in all cases (Roopnarine 1995). Static allometry was assessed within each sample by regression of shape scores on centroid size (the only multivariable measure of size that is uncorrelated with shape in the absence of allometry), but no significant allometry was detected within any sample.

\section{Drilling morphometry}

Samples of drilled specimens were drawn from those used in the morphometric 
analysis, but in some cases exceed the sample sizes used for morphometric description. Samples are (sample sizes in parentheses): Pinecrest Beds (89), Caloosahatchee Fm. (11), Bermont Fm. (102), Ft. Thompson Fm. (101), Recent (32). The Anastasia Fm. was excluded because of small sample size, and the results from the Caloosahatchee Fm. should be treated cautiously for the same reason. The frequency of drilling was not measured because the samples were not derived from bulk samples.

Three drilling parameters were documented for the two Chione species: drill hole location, drill hole size, and valve thickness. Prey size was assessed as maximum valve height, and outer drill hole diameter served as a proxy for predator size (Kitchell et al. 1981). All measures were made with digital calipers to the nearest $0.01 \mathrm{~mm}$, except valve thickness, which was measured at the ventral margin of the valve with a micrometer screw gauge to the nearest $0.01 \mathrm{~mm}$. Hole location was mapped onto a valve using the image techniques and morphometric baseline described above to record the geometric location of the hole. In this respect, the hole centroid is treated as a landmark of the shell. Selectivity

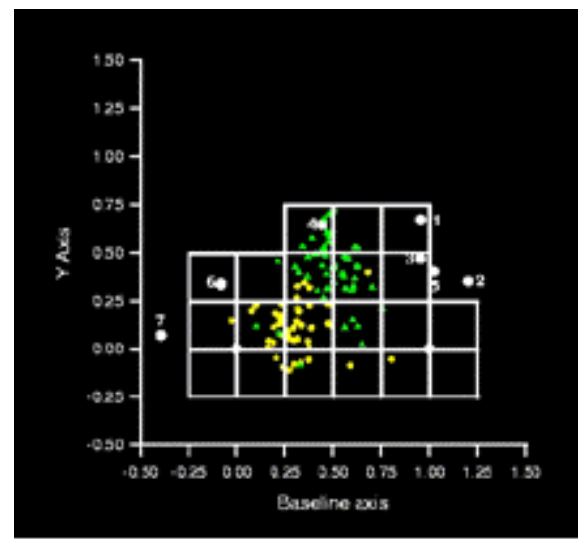

Figure 5. and randomness of hole location were tested by dividing the available valve surface into 20 equal area sectors (Figure 5), recording the frequency of drilling in each sector, for each sample, and comparing sample means and variance with likelihood ratio tests (Manly 1986) of means and mean deviations respectively.

Relationships between drill hole diameter and valve height, and valve thickness and height, were formulated using Model II regression of log transformed values. The significance and equality of regression parameters were tested by comparison of bootstrapped percentile confidence intervals based on 1,000 regression iterations (Efron and Tibshirani 1993).

\section{RESULTS}

Morphometric comparisons 
Multivariate analysis of variance (MANOVA) and canonical variates analysis (CVA) of the resulting uniform and non-uniform shape scores confirmed the significant discrimination between Pliocene and postPliocene samples (Wilks' lambda, $P<0.01$; Fig. 6). Only the first canonical factor discriminated significantly among the samples.

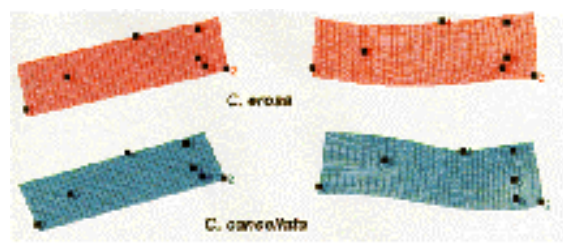

Figure 7 .

The morphological bases for the discrimination can be visualized with thinplate splines of the

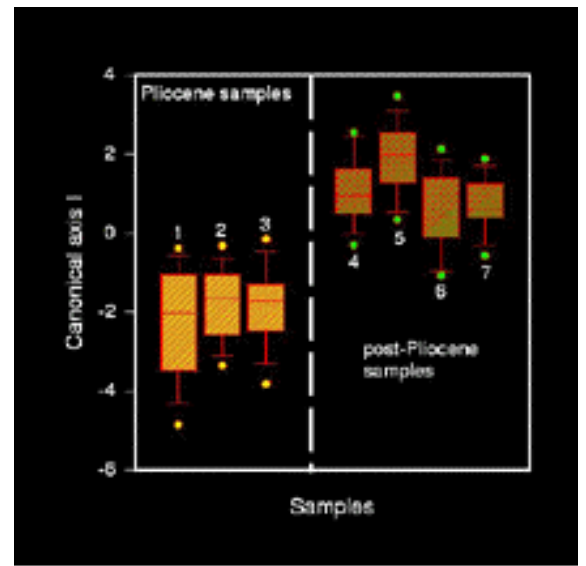

Figure 6. transformations (Fig. 7). The uniform analyses illustrate $\mathbf{C}$. erosa as a sheared transformation, compared to C. cancellata. This is reflective of the observed greater circularity of the $\mathbf{C}$. cancellata valve outline, and the relatively longer escutcheon of $\mathbf{C}$. erosa. The non-uniform splines indicate that the major difference between these two species are the relative placements of the anterior cardinal tooth and the dorsal tip of the anterior adductor muscle scar (landmarks 3 and 5 respectively) that results in $\mathbf{C}$. erosa having a broader and deeper hinge relative to $\mathbf{C}$. cancellata. Also apparent is the relatively shorter lunule of $\mathbf{C}$. cancellata (visualized as the distance between landmarks 1 and 2), as noted in previous studies (Dall, 1903; Roopnarine, 1995)

\section{Naticid predation}

Naticid drill hole location was found to be selective and non-random within all samples (chi ${ }^{2}$ goodness-of-fit test; $\mathrm{P}<0.05$ for all samples), and the mean and variance of hole location varied significantly among samples. The mean location of drilling was the same for the Pliocene Pinecrest Beds and Caloosahatchee Fm., the Lower Pleistocene Bermont Fm. and the Recent, but differed significantly for the Middle Pleistocene Ft. Thompson Fm. (likelihood ratio test of sample means (Manly, 1986); $P<0.001$ ). The mean location of drilling in the latter sample is on the dorso-posterior region of the valve, whereas it is situated close to the ventral end of the posterior adductor muscle in the other samples (Fig. 5). The most obvious difference however between Pliocene and post-Pliocene valves, is found in the variance of drill hole location. There is a significantly

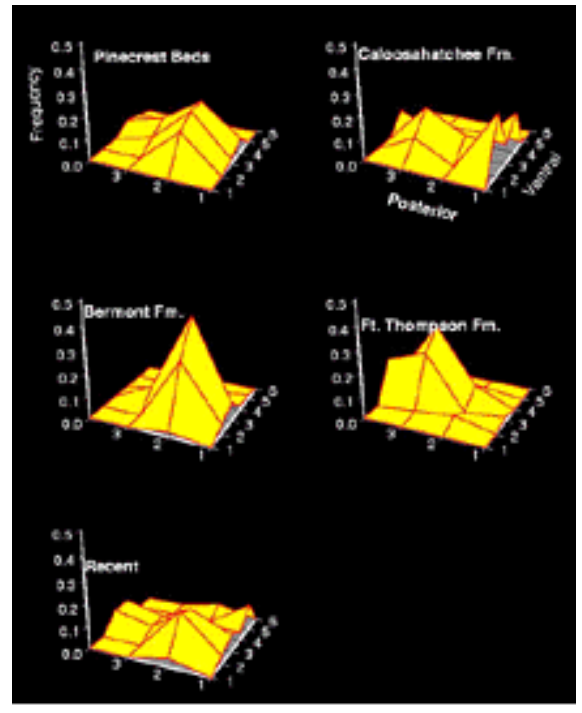

Figure 8. 
smaller spatial distribution of drill holes in samples from the Bermont and Ft. Thompson formations when compared to those from the Pliocene Pinecrest Beds and the Caloosahatchee Fm. (likelihood ratio test of deviations from the mean; $P<0.001$ ), but the Recent sample exhibits as much variation as pre-extinction samples (Fig. 8). This can be explained by noting that in addition to being drilled in the "typical" posterior adductor region, Recent specimens are also drilled frequently on the dorso-posterior region, typical of Middle Pleistocene specimens from the Ft. Thompson Fm.

Model II regression analysis of the relationship between drill hole size (estimate of predator size) and prey size indicates a change after the end of the Pliocene. The relationship between these two parameters is statistically significant before the Pleistocene, but only marginally significant during Bermont time (Fig. 9). Naticids of all sizes seem to prey upon Chione in a medium size range. By the Middle Pleistocene (Ft. Thompson Fm.) however, prey selection is again stereotyped by prey size. Reduction in stereotypy of prey size selection is predicted by the Kelley-Hansen Hypothesis.

There is no corresponding change in valve thickness. In fact, individuals of $\mathbf{C}$. cancellata from the Bermont Fm. were of almost identical thickness to the Pliocene $\mathbf{C}$. erosa (Figure 10). During the Pleistocene however, valve thickness of C. cancellata increased significantly, and remains significantly greater today.

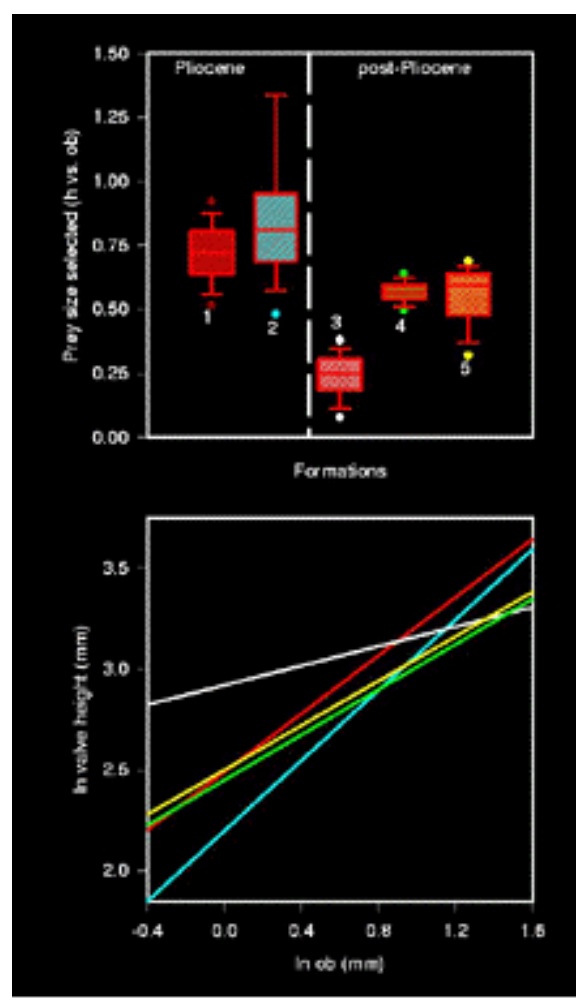

Figure 9.

\section{DISCUSSION}

The temporally consistent morphometric distinction between Pliocene and post-Pliocene specimens suggests that post-Pliocene specimens are assignable to a different species, or represent significant intraspecific geographic variation (Roopnarine 1995).

Recognition of pseudosurvivor taxa such as C. cancellata is an important dimension in the study of extinction in the fossil record. Extinction intensities could be underestimated if pseudosurvivor taxa are not recognized. Such taxa may originate as cladogenetic descendants of the species that suffered extinction, or by the immigration of morphologically similar taxa into the region affected by the extinction. 
Vermeij suggested that the process of escalation may be more evident in cases of the geographic replacement of a lineage that suffers extinction or habitat restriction, compared to cases of within-lineage evolution (Vermeij 1987). This study demonstrates both situations. After the extinctions, at the end of the Caloosahatchee Fm., there is a significant and dramatic decrease in the stereotypy of prey size selection by naticids of any given size (Fig. 9 ) in the Lower Pleistocene Bermont Fm. This could indicate that the Chione cancellata that were replacing the now extinct $\mathbf{C}$. erosa were more escalated than their C. erosa predecessors, thereby forcing larger predators to select smaller, less escalated individuals. However, this interpretation can be refuted by three lines of

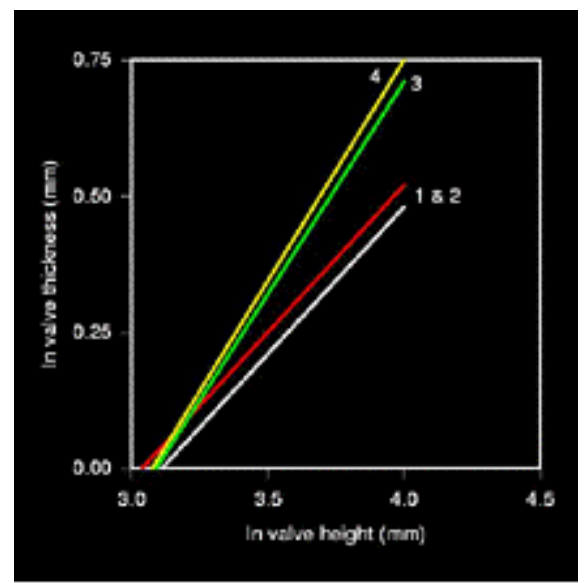

Figure 10. evidence: (1) The most obvious anti-predatory trait on the shells of the two species is the elaborate concentric sculpture. While the sculpture probably functions to stabilize shells in sediment (Stanley 1970), it may also serve as an impediment to successful drilling (Vermeij 1980; Kitchell et al. 1981). Chione erosa however possessed much more elaborate and extensive sculpture than $\mathbf{C}$. cancellata. (2) While body size does not vary significantly among our samples, C. erosa attained larger body sizes in general than did post-Pliocene C. cancellata (Roopnarine 1996). (3) Examination of the ontogenetic development of valve thickness in both species reveals that there was no significant difference between thickness of Pliocene Chione valves and those found in the Bermont Fm. (Fig. 10). Naticid predators therefore, were definitely not presented with a more escalated prey species when $\mathbf{C}$. cancellata replaced C. erosa in the Early Pleistocene. Interestingly, absolute valve thickness of $\mathbf{C}$. cancellata increased significantly through the Pleistocene and into the Recent, as shown by the relationship between valve thickness and size (Fig. 10). The reason for the increase of valve thickness is unknown, but could be the result of environmental factors, or escalation in response to predation. A number of environmental factors are known to influence shell size in bivalves, including water temperature. Warmer temperatures promote shell deposition, perhaps making it easier to mineralize a thicker shell, and coastal waters off Florida may have been slightly cooler during the Pliocene than they are today because of seasonal upwelling (Allmon et al. 1996). The subsequent post-Pliocene warming might therefore have made it possible for $\mathbf{C}$. cancellata to increase valve thickness, but drilling mediated selection would ultimately reinforce the trend by favouring thicker shells.

There is a distinct possibility that some of these pattern can be explained by turnover in the naticid fauna itself. However, of the eight species of naticids known from the Floridian Pliocene, five are extant today. The Recent naticid fauna comprises approximately 14 species. In their compilation of post-Pliocene gastropod immigration to the tropical western Atlantic, Vermeij and Rosenberg found no evidence of naticid participation (Vermeij and Rosenberg 1994). 
We hypothesize that the reduction in the stereotypy of prey size selection after the PlioPleistocene transition is a result of the different morphologies of $\mathbf{C}$. erosa and $\mathbf{C}$.

cancellata interacting with naticid prey-handling behaviours. A stereotyped, unchanging handling behaviour may present novel challenges to the predator when faced with new prey, or the naticids may have altered their behaviours to cope with the new prey. The reduction of stereotypy was not the result of a new, more escalated prey taxon. Nevertheless, by the middle of the Pleistocene (Ft. Thompson Fm.), predation recovered somewhat, and selected prey size increased. But the mean location of drill holes also changed, suggesting an adjustment of predatory behaviour, or the appearance of new naticid species. These changes in size selection persist to the Recent. From the Middle Pleistocene on, specimens of $\mathbf{C}$. cancellata have significantly thicker valves than either their conspecific ancestors or $\mathbf{C}$. erosa, apparently escalating their defenses as a result of naticid drilling predation and the biogeographic effects of a regional mass extinction.

The reduction in the variation of drill hole location in the Pleistocene compared to the pre-extinction Pliocene does not seem to support Kelly and Hansen's prediction of a reduction in stereotypy, while prey size selection indicates the converse. These observations suggest that the reaction of predator-prey systems to extinction and replacement of prey species is more likely to be a mosaic of predatory responses, rather than a single and overall reduction of stereotypy. Moreover, because of the morphological similarity between the prey taxa, we may not expect the Kelley-Hansen hypothesis to necessarily be relevant in situations of geographic replacement. This further supports the need for careful morphological studies when assessing the ecological and evolutionary consequences of extinctions.

\section{ACKNOWLEDGMENTS}

We thank D. Jones, R. Portell and E. Vokes for collection of and access to many of the specimens. L. Anderson, S. Bursten, K. Driver, K. Flessa, L. Leighton and G. Vermeij provided helpful comments and discussion, and P. Kelley and an anonymous reviewer provided helpful comments on the manuscript. We are greatly indebted to L. Schuff for assistance in data collection. This document was prepared with LATEX and the th (TEX to HTML) converter (I. Hutchinson). 


\section{REFERENCES}

Allmon, W. D., Emslie, S. D., Jones, D. S., and Morgan, G. S. 1996. Late Neogene oceanographic change along Florida's west coast: Evidence and mechanisms. Journal of Geology, 104:143-162.

Allmon, W. D., Rosenberg, G., Portell, R. W., and Schindler, K. S. 1993. Diversity of Atlantic Coastal Plain mollusks since the Pliocene. Science, 260:1626-1629.

Anderson, L. C., Geary, D. H., Nehm, R. H., and Allmon, W. D. 1991. A comparative study of naticid gastropod predation on Varicorbula caloosae and Chione cancellata, Plio-Pleistocene of Florida, U.S.A. Palaeogeography, Palaeoclimatology, Palaeoecology, 85:29-46.

Bookstein, F. L. 1991. Morphometric Tools for Landmark Data. Cambridge University Press, New York.

Dall, W. H. 1903. Tertiary fauna of Florida: Veneridae. Transactions of the Wagner Free Institute of Science, 3:1219-1334.

Efron, B. and Tibshirani, R. J. 1993. An Introduction to the Bootstrap. Monographs on Statistics and Applied Probability 57. Chapman and Hall, New York.

Fursich, F. T. and Jablonski, D. 1984. Late Triassic naticid drillholes: carnivorous gastropods gain a major adaptation but fail to radiate. Science, 224:78-80.

Hansen, T. A. and Kelley, P. H. 1995. Spatial variation of naticid gastropod predation in the Eocene of North America. PALAIOS, 10:268-278.

Jackson, J. B. C., Jung, P., Coates, A. G., and Collins, L. S. 1993. Diversity and extinction of tropical American mollusks and emergence of the Isthmus of Panama. Science, 260:1624-1626.

Jones, D. S. and Allmon, W. D. 1995. Records of upwelling, seasonality, and growth in stable isotope profiles of Pliocene mollusk shells from Florida. Lethaia, 28:61-74.

Kelley, P. H. 1989. Evolutionary trends within bivalve prey of Chesapeake Group naticid gastropods. Historical Biology, 2:139-156.

Kelley, P. H. 1991. The effect of predation intensity on rate of evolution of five Miocene bivalves. Historical Biology, 5:65-78.

Kelley, P. H. and Hansen, T. A. 1996. Recovery of the naticid gastropod predator-prey system from the Cretaceous-Tertiary and Eocene-Oligocene extinctions. In Hart, M. B., editor, Biotic Recovery from Mass Extinction Events, p. 373-386. Geological Society Special Publication No. 102.

Kendall, D. G. 1986. Comment on F. L. Bookstein, Size and shape spaces for landmark 
data in two dimensions. Statistical Science, 1:222-226.

Kitchell, J. A., Boggs, C. H., Kitchell, J. F., and Rice, J. A. 1981. Prey selection by naticid gastropods: experimental tests and application to the fossil record.

Paleobiology, 7:533-552.

Linnaeus, C. 1767. Systema Naturae per regna triae naturae. editio duodecima, retormata. Volume 1, Regnum animale, (2):533-1327.

Manly, B. F. J. 1986. Multivariate Statistical Methods: A Primer. Chapman and Hall, New York.

Rohlf, F. J. 1996. Morphometric spaces, shape components and the effects of linear transformation. In Marcus, L. F., Corti, M., Loy, A., Naylor, G. J. P., and Slice, D. E., editors, Advances in Morphometrics, pages 117-129. Plenum Press, New York and London.

Rohlf, F. J. 1997. TPSRW-Thin-plate spline relative warp. Department of Ecology and Evolution, State University of New York, Stony Brook, New York 11794.

Roopnarine, P. D. 1995. A re-evaluation of evolutionary stasis between the bivalve species Chione erosa and Chione cancellata (Bivalvia: Veneridae). Journal of Paleontology, 69(2):280-287.

Roopnarine, P. D. 1996. Systematics, biogeography and extinction of chionine bivalves (Early Oligocene - Recent) in the Late Neogene of tropical America. Malacologia, 38:103-142.

Roopnarine, P. D. 1997. Endemism and extinction of a new genus of chionine (Bivalvia: Veneridae) bivalve from the late Neogene of Venezuela. Journal of Paleontology, 71:1039-1046.

Sheehan, P. M. and Lesperance, P. J. 1978. Effect of predation on the population dynamics of a Devonian brachiopod. Journal of Paleontology, 52:812-817.

Slice, D. E. 1996. Introduction to landmark methods. In Marcus, L. F., Corti, M., Loy, A., Naylor, G. J. P., and Slice, D. E., editors, Advances in Morphometrics, pages 113115. Plenum Press, New York and London.

Slice, D. E., Bookstein, F. L., Marcus, L. F., and Rohlf, F. J. 1996. Appendix I: A glossary for geometric morphometrics. In Marcus, L. F., Corti, M., Loy, A., Naylor, G. J. P., and Slice, D. E., editors, Advances in Morphometrics, pages 531-551. Plenum Press, New York and London.

Stanley, S. M. 1986. Anatomy of a regional mass extinction: Plio-Pleistocene decimation of the Western Atlantic bivalve fauna. Palaios, 1:17-36.

Stanley, S. M. 1970. Relation of shell form to life habits of the Bivalvia (Mollusca). 
Geological Society of America Memoir, 125:1-296.

Teranes, J. L., Geary, D. H., and Bemis, B. E. 1996. The oxygen isotopic record of seasonality in Neogene bivalves from the Central American Isthmus. In Jackson, J. B. C., Budd, A. F., and Coates, A. G., editors, Evolution and Environment in Tropical America, pages 105-129. The University of Chicago Press.

Vermeij, G. J. 1980. Drilling predation in a population of the edible bivalve Anadara granosa. Nautilus, 94:123-125.

Vermeij, G. J. 1987. Evolution and Escalation. An ecological history of life.

Princeton University Press, Princeton, New Jersey.

Vermeij, G. J. and Petuch, E. J. 1986. Differential extinction in tropical American molluscs: Endemism, architecture, and the Panama land bridge. Malacologia, 17:2941.

Vermeij, G. J. and Rosenberg, G. 1994. Giving and receiving: The tropical Atlantic as donor and recipient region for invading species. American Malacological Bulletin, 10:181-194.

Woodring, W. P. 1966. The Panama land bridge as a sea barrier. American Philosophical Society Transactions, 110:425-433. 
Figure 1. Right valves of $A$ ) Chione erosa from the lower Pincecrest Beds (Lower Pliocene), and B) C. cancellata from the Recent of Florida. Note the naticid drill hole in A. Scale = A) $5 \mathrm{~mm}$, and B) $10 \mathrm{~mm}$. Specimens are from the author's collection.
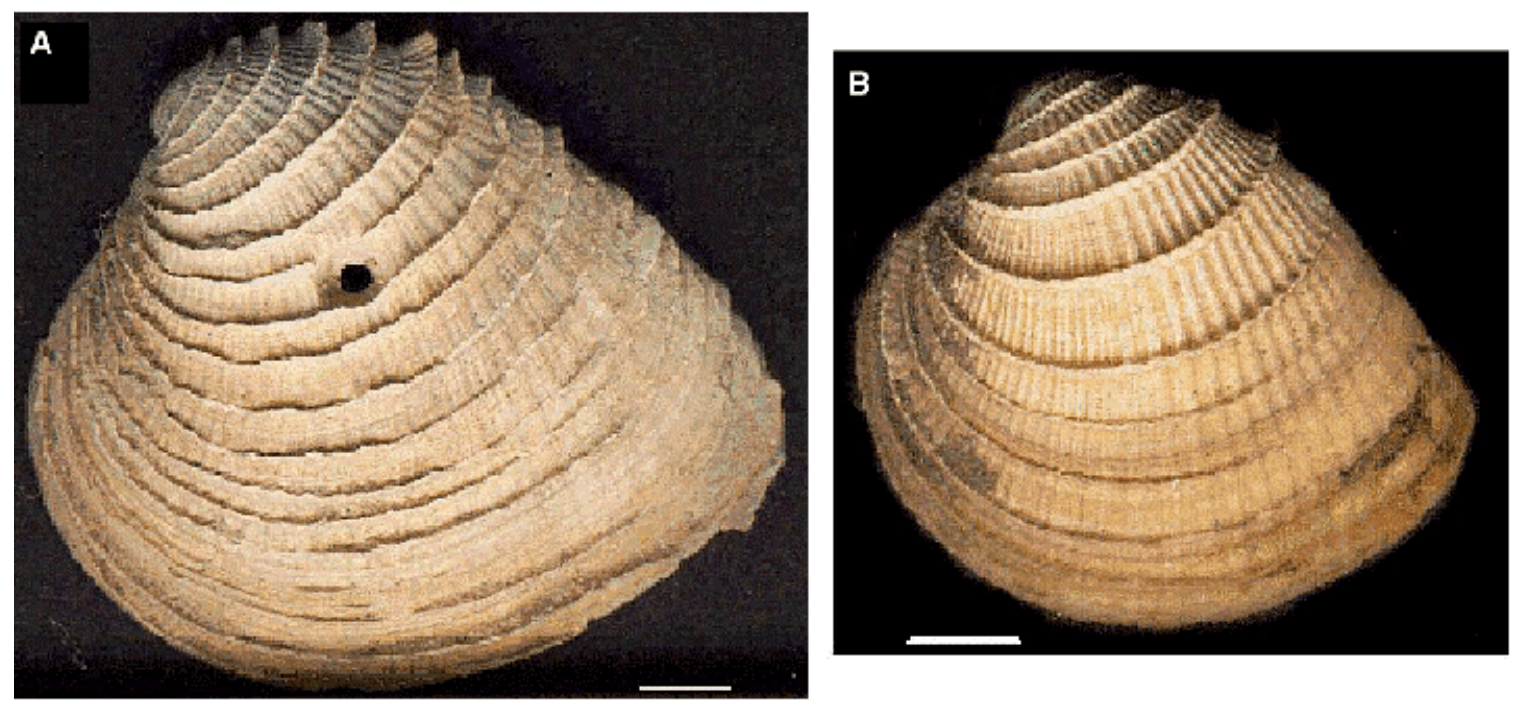
Figure 2. Close-up of the naticid drill hole shown in Figure 1. Diameter of the drill hole (white line) is $4.17 \mathrm{~mm}$.

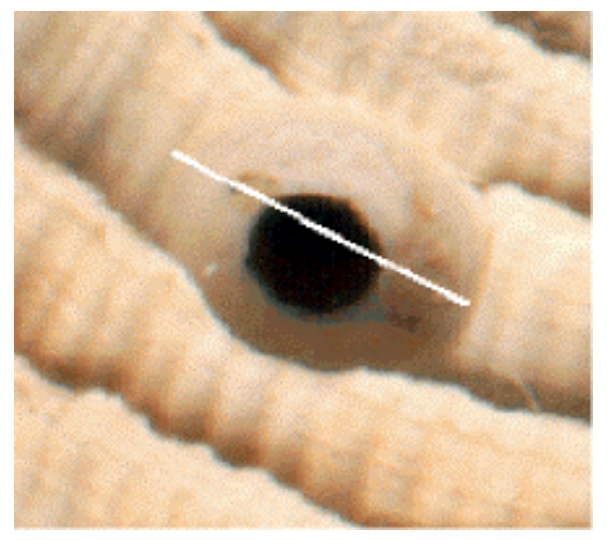


Figure 3. Schematic stratigraphic chart of Late Neogene/Pleistocene deposits in south Florida.

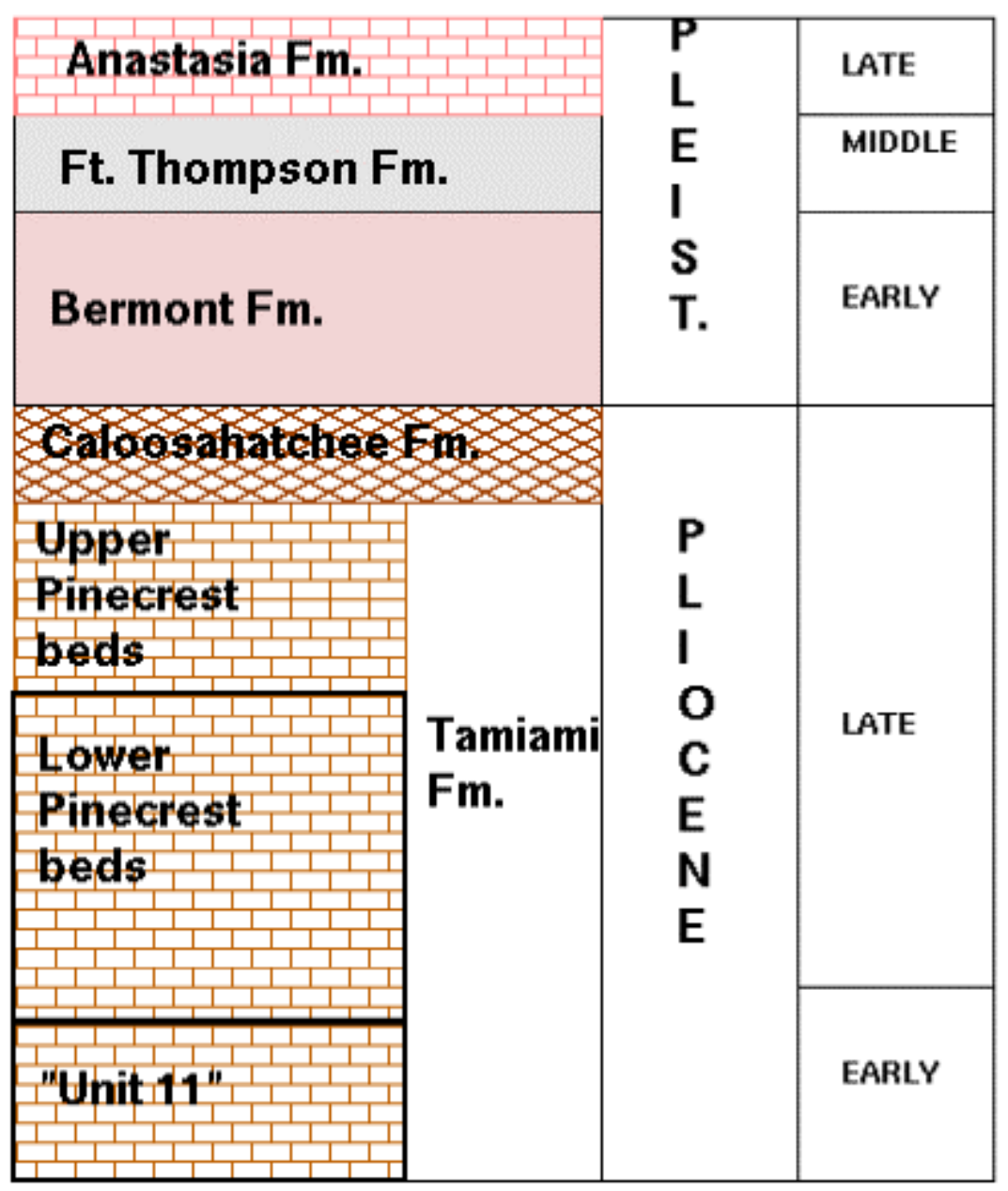


Figure 4. Homologous landmarks selected for morphometric description. A - umbo, B ventral end of lunule, $C$ - ventral end of anterior cardinal tooth, D - ventral end of posterior cardinal tooth socket, $\mathrm{E}$ - dorsal terminus of anterior adductor muscle scar, $\mathrm{F}$ ventral intersection of anterior adductor muscle scar and pallial line, $\mathrm{G}$ - dorsal terminus of posterior adductor muscle scar, $\mathrm{H}$ - intersection of margin of posterior adductor muscle scar and pallial sinus, I - ventral end of escutcheon. Landmarks $\mathrm{F}$ and $\mathrm{H}$ represent the baseline $([1,0]$ and $[0,0]$ respectively) for computation of shape coordinates.

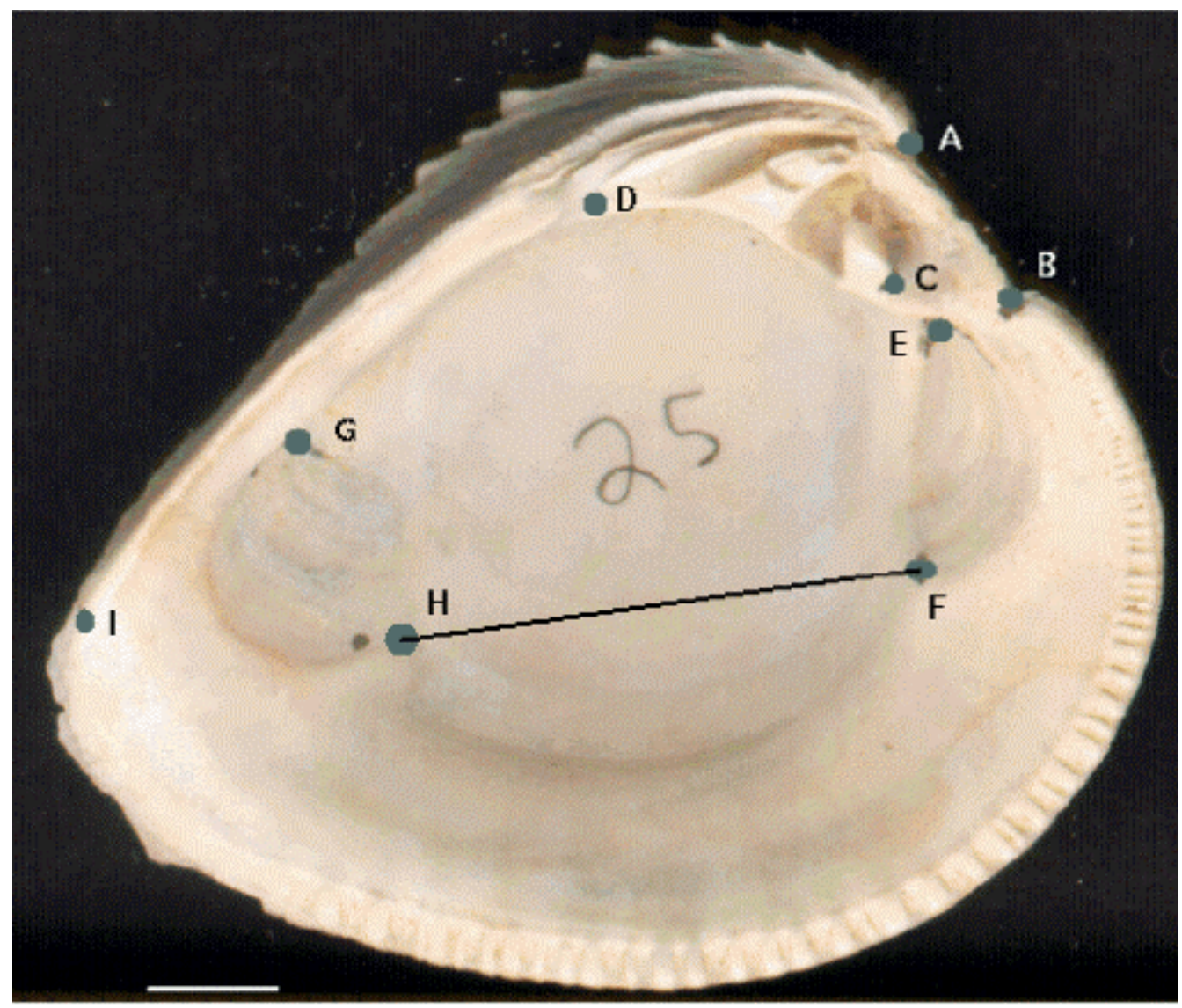


Figure 5. Distribution of equal-area quadrats on the surface of a valve. Numbers mark the location of landmarks used in the morphometric analysis. Open circles are the locations of drill holes on specimens from the Bermont Fm., filled triangles are those from the Ft. Thompson Fm. Note the more dorsal concentration of drill holes in the Ft. Thompson specimens.

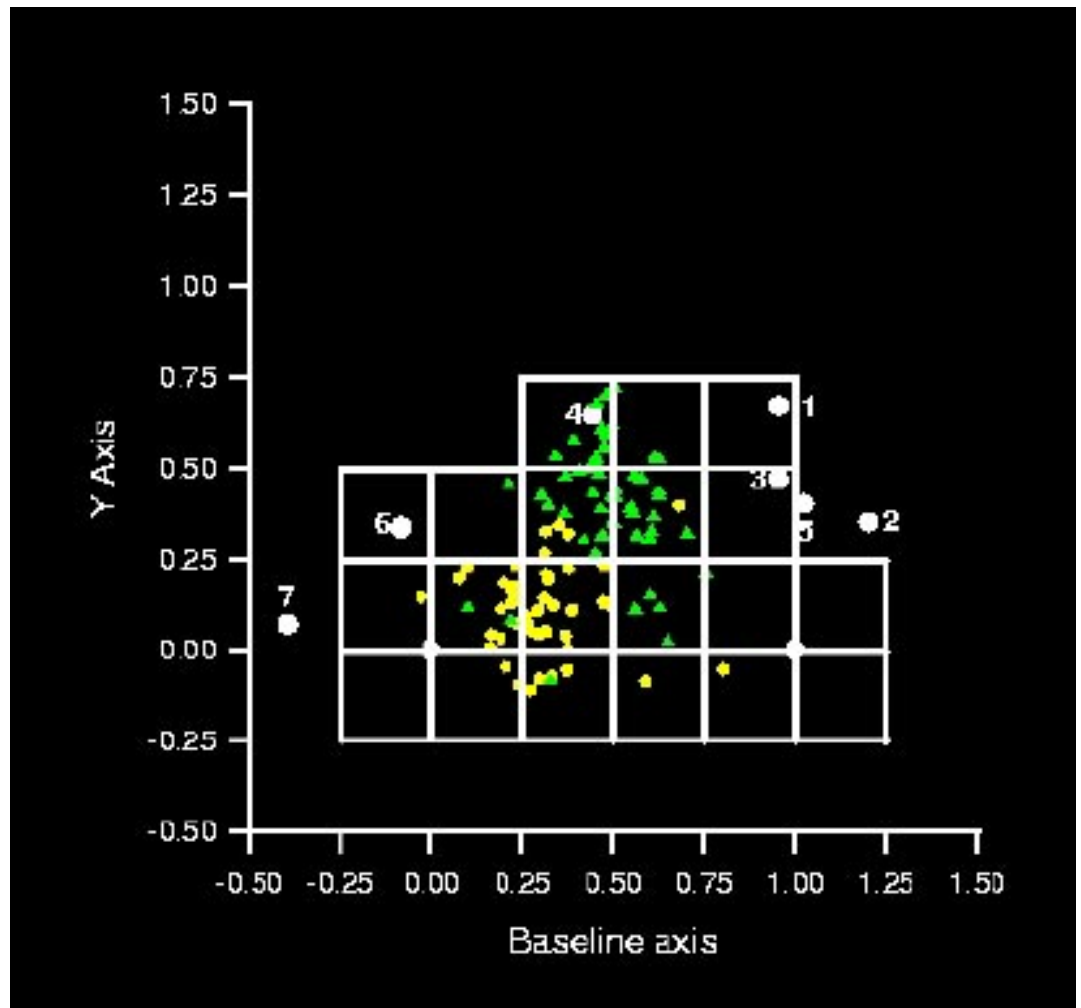


Figure 6. Distribution of canonical scores on the first canonical axis, from CVA of the morphometric data. Vertical dashed line separates Pliocene from post-Pliocene samples. Sample numbers are: 1 - middle Pliocene Jackson Bluff Fm. (northwest Florida), 2 - middle-Upper Pliocene Pinecrest Beds (west central Florida), 3 - Upper Pliocene Caloosahatchee Fm. (central Florida), 4 - Lower Pleistocene Bermont Fm. (west central Florida), 5 - Middle Pleistocene Ft. Thompson Fm. (west central Florida), 6 - Upper Pleistocene Anastasia Fm. (east central Florida), and 7 - Recent (east central Florida). These results reproduce those presented previously by Roopnarine (1995), but are based on narrower geographic coverage.

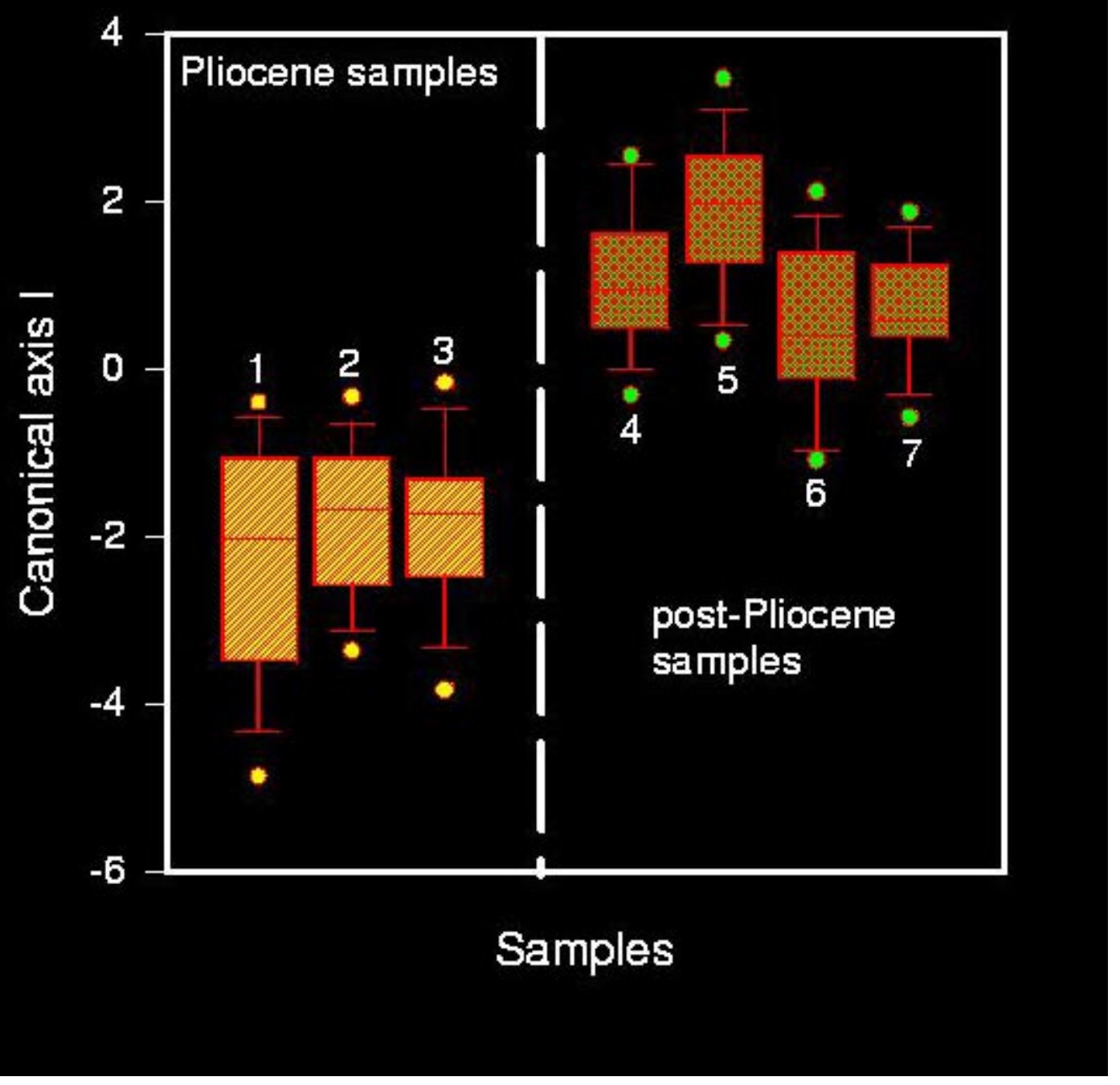


Figure 7. Thin plate spline representations of uniform (left) and non-uniform (right) transformations. Landmarks are: 1 - umbo, 2 - ventral end of lunule, 3 - ventral end of anterior cardinal tooth, 4 - ventral end of posterior cardinal tooth, 5 - dorsal end of anterior adductor muscle scar, 6 - dorsal end of posterior adductor muscle scar, 7 ventral end of escutcheon. Baseline comprises the intersection of the posterior adductor muscle scar and pallial line $(0,0)$, and the ventral intersection of the adductor muscle scar and pallial line $(1,0)$.

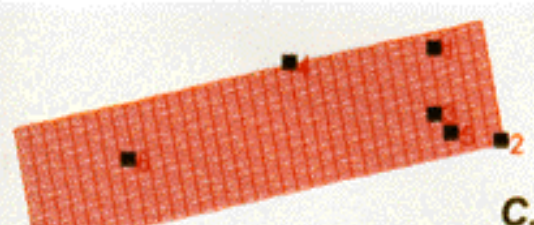

C. erosa
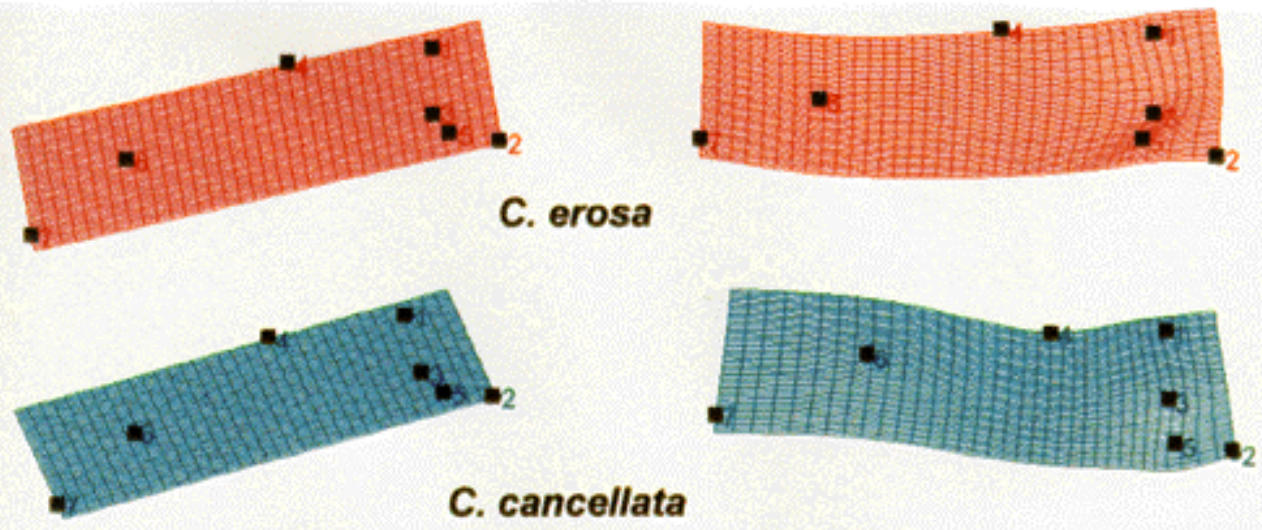

C. cancellata 
Figure 8. Distribution of drill holes on valve surfaces during each geological formation. The xy plane represents the grid illustrated in Figure 5. $z$ axis represents the frequency of drilling per quadrat.
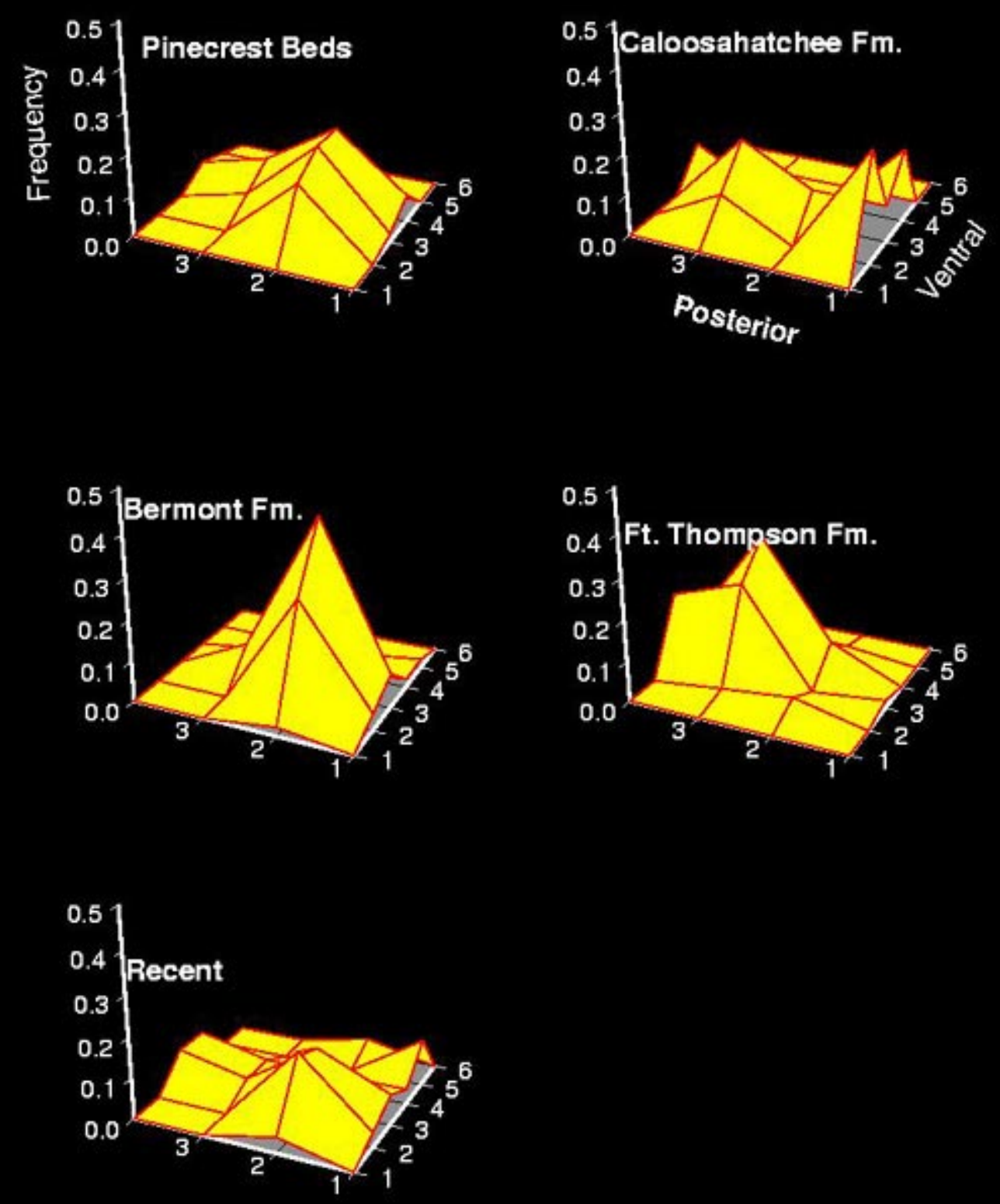
Figure 9. A) Intersample comparison of prey size selection. Each box represents the distribution of slopes for 1,000 bootstrap iterations of valve height $(h)$ regressed on outer drill hole diameter (ob). Vertical dashed line marks the Plio-Pleistocene transition. Sample numbers are: 1 - Pinecrest Beds, 2 - Caloosahatchee Fm., 3 - Bermont Fm., 4 Ft. Thompson Fm., and 5 - Recent. The samples differ statistically only among their regression slopes (intercepts are not statistically different), and fall into three statistically distinct groups: (1) The Pliocene Pinecrest Beds $(h=(0.720 b)+2.49[\mathrm{P}<0.001])$ and Caloosahatchee Fm. $(h=(0.87 \mathrm{ob})+2.20[P=0.005])$, (2) the Lower Pleistocene Bermont Fm. $(\mathrm{h}=(0.24 \mathrm{ob})+2.92[\mathrm{P}=0.001])$ and $(3)$ the Middle Pleistocene Ft. Thompson Fm. ( $\mathrm{h}$ $=(0.56 \mathrm{ob})+2.45[\mathrm{P}=0.019])$ and the Recent $(\mathrm{h}=(0.55 \mathrm{ob})+2.50[\mathrm{P}<0.001])$. B) Plot of the regressions relationships summarized in (A). Colors follow those of the symbols in (A): red - Pinecrest Beds, cyan - Caloosahatchee Fm., white - Bermont Fm., yellow - Ft. Thompson Fm. and green - Recent. The figure demonstrates clearly the significant decrease in the stereotypy of prey size selectivity associated with the Plio-Pleistocene transition, followed by an increase during Ft. Thompson time. 


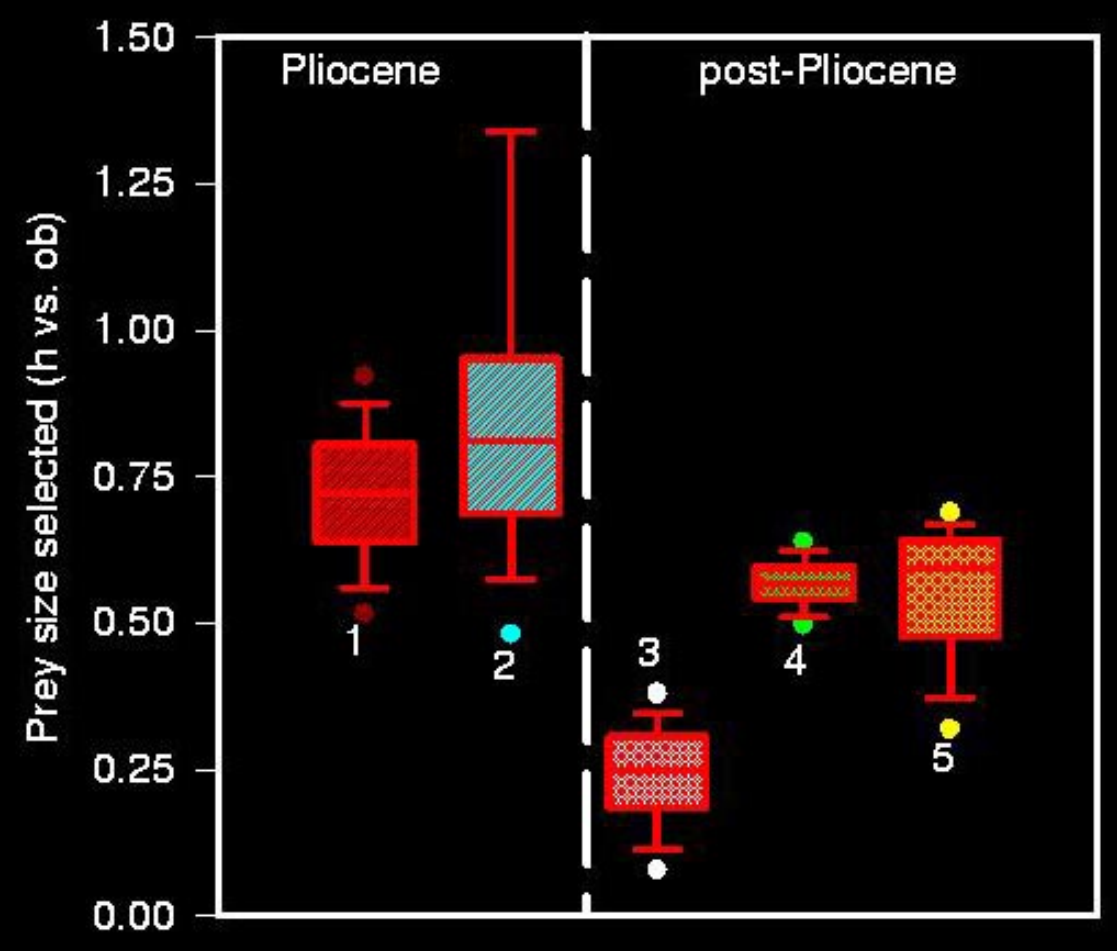

Formations

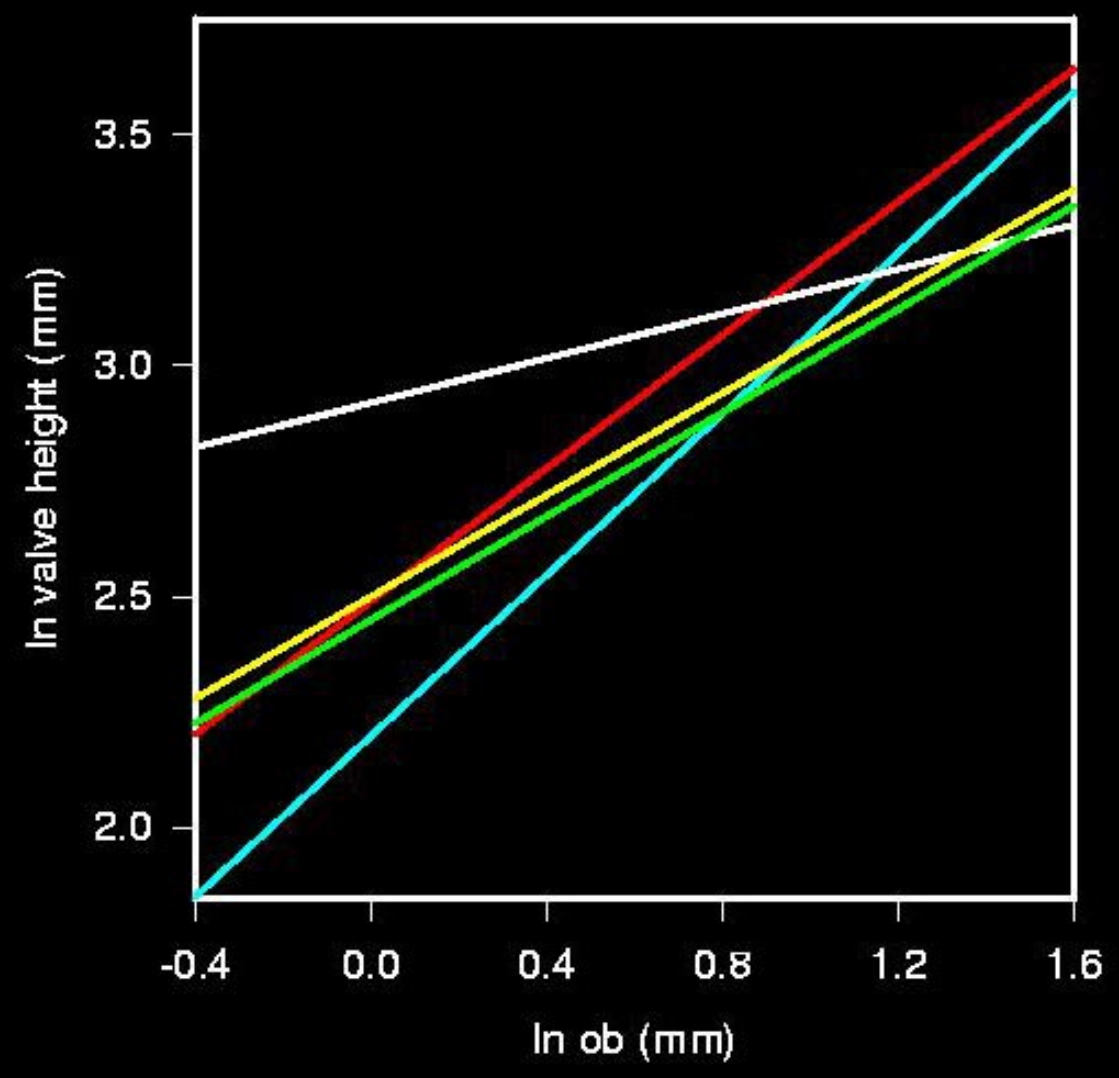


Figure 10. Valve thickness (t) regressed on valve height (h). Each line represents the median line of 1,000 bootstrap iterations. Sample numbers are: 1 - Pinecrest Beds, 2 Bermont Fm., 3 - Ft. Thompson Fm., and 4 - Recent. The Caloosahatchee Fm. was excluded because of the lack of a significant regression (due possibly to an insufficient sample size $)$. Lines 1 and $2(t=(0.54 h)-1.68[P<0.001]$ and $t=(0.54 h)-1.64[P=0.007]$ respectively) are statistically indistinguishable, as are lines 3 and $4(\mathrm{t}=(0.78 \mathrm{~h})-2.41$ $[P<0.001]$ and $t=(0.81 \mathrm{~h})-2.49[\mathrm{P}<0.001]$ respectively $)$. Both pairs are however statistically distinct from each other, reflecting the significant increase of valve thickness from the Middle Pleistocene on. The lines were plotted to a valve height of $36 \mathrm{~mm}$, which is the approximate mean height of over 700 measured specimens of both C. erosa and C. cancellata (Roopnarine, 1996).

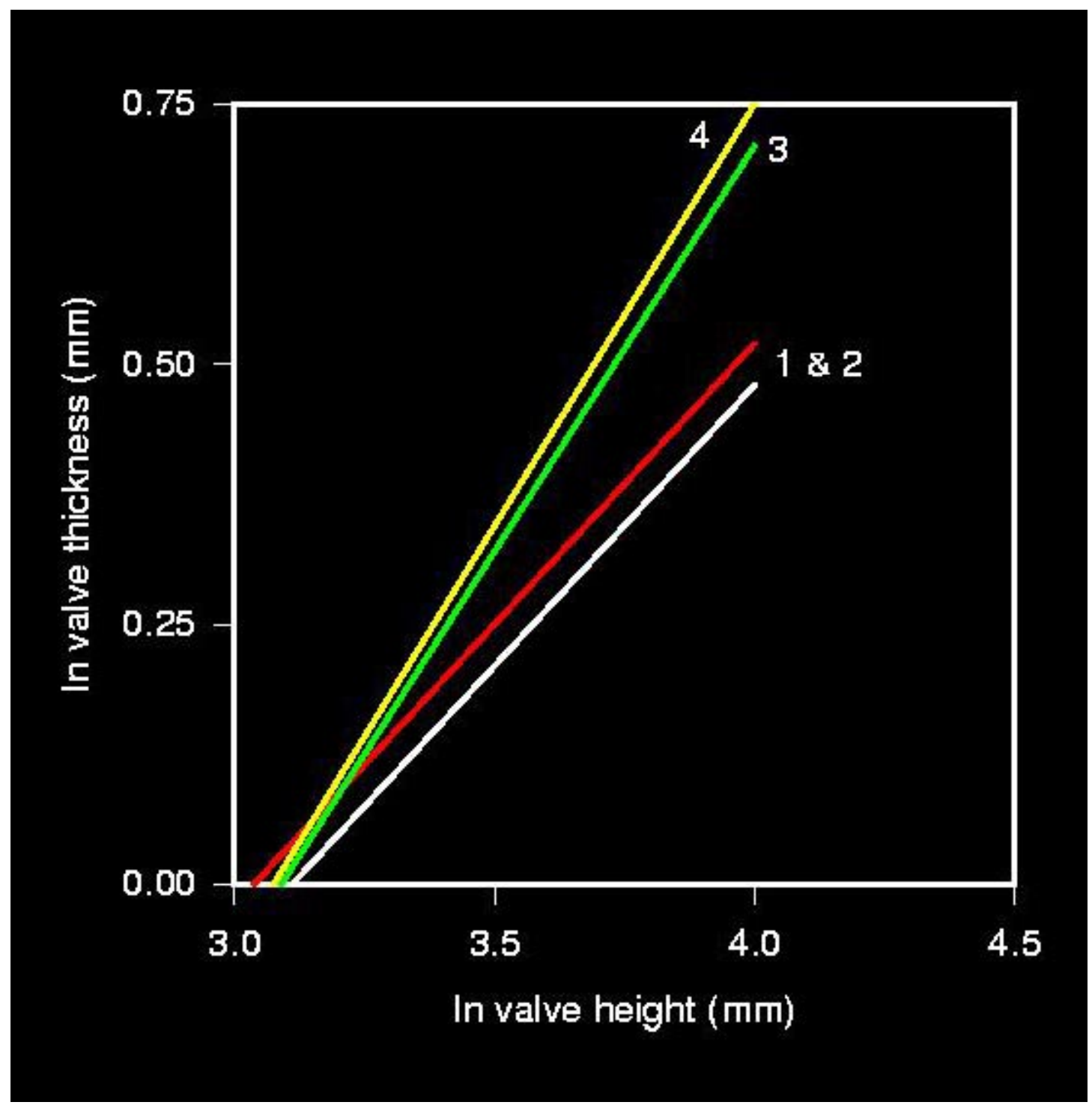

